\title{
Different Processes for Different Therapies: Therapist Actions, Therapeutic Bond, and Outcome
}

\author{
Pål G. Ulvenes, Lene Berggraf, and Asle Hoffart \\ Modum Bad Psychiatric Center, Vikersund, Norway and \\ University of Oslo
}

\author{
Tore C. Stiles \\ Norwegian University of Science and Technology
}

Martin Svartberg

Diakonhjemmet Hospital, Oslo, Norway

\author{
Leigh McCullough \\ Modum Bad Psychiatric Center, Vikersund, Norway and \\ Harvard Medical School
}

\author{
Bruce E. Wampold \\ Modum Bad Psychiatric Center, Vikersund, Norway and University of Wisconsin-Madison
}

\begin{abstract}
Therapeutic bond, as a component of the alliance, is considered a common factor in psychotherapy; however, it may operate differently in various treatments. This article investigates therapist actions, particularly affect focus, in the formation of the bond and on reduction of symptoms in short-term dynamic psychotherapy (STDP) and cognitive therapy (CT) for cluster C patients. Forty-six cases (23 STDP and 23 CT) were assessed using the Psychotherapy Process Q-Sort, the Helping Alliance Questionnaire, and the Symptom Checklist 90. These scores were used to determine (a) therapist actions that predict formation of the bond, (b) the relation of the bond to symptom reduction, and (c) how therapist actions and bond interacted to reduce symptoms. Multiple regressions were applied to the total sample and to the STDP and CT cases. Psychotherapy Process Q-Sort items describing avoidance of affects were positively related to the bond in the total sample, STDP and CT. However, the relation between therapist actions, bond, and symptom reduction differed for the two treatments. For STDP, avoidance of affect suppressed the relation of bond to symptom reduction and also negatively influenced symptom reduction. On the other hand, in CT, avoidance of affect was positively related to both the formation of the bond and to symptom reduction. Although the bond is a common factor and important component of the alliance, it appears to operate differently in STDP and CT. A focus on affect is important to the benefits of STDP but interferes with the benefits of CT.
\end{abstract}

Keywords: alliance, therapist actions, cognitive therapy, dynamic therapy, personality disorders

The most recent meta-analysis on the working alliance in individual psychotherapy identified nearly 200 independent studies that investigated the relationship between alliance and outcome (Horvath, Del Re, Flückiger and Symmonds, 2011). The Horvath et al. (2011) meta-analysis reported an aggregate correlation between alliance and outcome of .275 , which is a moderate-to-large effect. The interest in the alliance is probably due to its pantheo-

Pål G. Ulvenes, Lene Berggraf, and Asle Hoffart, Research Institute, Modum Bad Psychiatric Center, Vikersund, Norway and Department of Psychology, University of Oslo, Oslo, Norway; Tore C. Stiles, Department of Psychology, Norwegian University of Science and Technology, Trondheim, Norway; Martin Svartberg, Department of Psychiatry, Diakonhjemmet Hospital, Oslo, Norway; Leigh McCullough, Research Institute, Modum Bad Psychiatric Center, Vikersund, Norway, and Harvard Medical School, Boston, Massachusetts; and Bruce E. Wampold, Research Institute, Modum Bad Psychiatric Center, Vikersund, Norway, and University of Wisconsin-Madison.

Correspondence concerning this article should be addressed to Pål Ulvenes, Forskningsinstituttet, Modum Bad, 3370 Vikersund, Norway. E-mail:pal.ulvenes@modum-bad.no retical nature as well as its well-documented and robust relationship with the outcome of psychotherapy (Norcross, 2011).

The importance of the alliance as a therapeutic factor, despite its robust relationship with outcome, is not firmly established for a number of reasons (see, e.g., DeRubeis, Brotman, Gibbons, 2005). DeRubeis et al. (2005), in a critique of nonspecific factors in psychotherapy, aptly observed that the alliance-outcome relationship may be due to (a) the therapist's ability to form the alliance, (b) the patient's characteristics that are facilitative of forming a relationship (e.g., the patient's social skills and attachment style), (c) an appropriate match of therapist and patient characteristics, or (d) earlier symptom change (i.e., before the alliance was measured). Baldwin, Wampold, and Imel (2007) investigated these various possibilities by disaggregating the total correlation between alliance and outcome into within and between therapist components (as well as the interaction). They found that therapists vary in their ability to form alliances with their patients and that this variability accounted for the correlation between alliance and outcome. Specifically, they found that those therapists who were better able to form strong alliances with their patients had better outcomes than therapists who were less able to form alliances with 
their patients. Moreover, it appeared that the patient's contribution to the alliance did not affect the outcome- that is, those patients who had better alliances with a given therapist did not have better outcomes than other patients of the same therapist who had poorer alliances. Finally, this research did not provide support for a matching effect or that the alliance was a result of early symptom change, although the evidence for the alliance as a consequence of early symptom change is ambiguous (see Barber, Connolly, CritsChristoph, Gladis, \& Siqueland, 2000; Crits-Christoph, Connolly Gibbons, Hamilton, Ring-Kurtz, \& Gallop., 2011; DeRubeis \& Feely, 1990; Feeley, DeRubeis, \& Gelfand, 1999; Klein et al., 2003; Tang \& DeRubeis, 1999; Webbet al., 2011). Nevertheless, the importance of therapists' ability to form an alliance for the outcome of psychotherapy has been replicated in a variety of settings (Dinger, Strack, Leichsenring, Wilmers, \& Schauenburg, 2008; Zuroff, Kelly, Leybman, Blatt, \& Wampold, 2010).

Although some theoretical orientations emphasize the importance of the alliance (e.g., humanistic/experiential therapists and some psychodynamic therapies) more than others (e.g., cognitivebehavioral therapies), the alliance seems to be critically important across therapeutic approaches (Flückiger, Del Re, Wampold, Symonds, \& Horvath, 2012; Horvath \& Bedi, 2002). Flückiger et al. (2012) investigated moderators of the alliance-outcome relation in a meta-analysis and found that neither research design, use of disorderspecific manuals, type of treatment, or specificity of outcome measures affected alliance-outcome relationship. However, it may well be that the components of the alliance (viz., bond, agreement about goals, agreement about tasks; Bordin, 1979, 1980, 1994) function differently in different therapies. Indeed, Webb et al. (2011) found that agreement about goals and tasks, but not the bond, were related to improvement subsequent to alliance measurements in cognitive therapy. Webb et al. (2011) argued that the relationship between the three components of the alliance might function differently for different types of therapy. Indeed, Bordin (1979) wrote that "some basic level of trust surely marks all variations of therapeutic relationships, but when attention is directed toward the more protected recesses of inner experience, deeper bonds of trust and attachment are required and developed" and "one bond may not necessarily be stronger than the other, but they do differ in kind" (p 254). Hatcher and Barends (2006) discussed how different therapies put different strains on the therapeutic bond, depending on the activity, commitments, and degree of personal involvement that is expected of the client (e.g., see p. 293).

Despite ambiguities in the literature, it appears that the therapist is critical to making the alliance therapeutic, and thus attention must be paid to what the therapist does to form an alliance that is therapeutic. In 2003, Ackerman and Hilsenroth comprehensively reviewed the therapist characteristics and actions that positively affect the alliance. They noted that little attention has been paid to this question, although they did identify 16 studies that investigated techniques and interventions used by therapists to facilitate the alliance. The literature suggested, according to Ackerman and Hilsenroth (2003), that the following characteristics and actions were related to development of the alliance: exploration, depth, reflection, support, past therapy success, accurate interpretation, facilitation of expression of affect, activity (vs. passivity), affirmation, understanding, and attention to the patient's experience. Hilsenroth and Cromer (2007) identified largely parallel findings when investigating formation of the alliance very early in therapy, indicating "that it is 'never too early' for clinicians to attempt to adopt these attitudes and interventions" (p. 210).

The relationships between therapist actions, the alliance, and outcome are unfortunately not straightforward. It may be problematic to assume that therapist characteristics and actions that are associated with the alliance are also important to therapeutic outcome based on the fact that the alliance is related to outcome. It could be, and would be very interesting if it were the case, that some therapist characteristics and actions might predict the alliance but not predict outcome- that is, these characteristics and actions predict a part of the alliance that is not related to outcome. For instance, the therapist might participate in actions that the patient finds agreeable but leads to an avoidance of real work in psychotherapy, as suggested by a case study in which the therapist subtly encouraged storytelling by the patient (Wampold \& Kim, 1989). There is a lack of research that has examined therapist actions, alliance, and outcome simultaneously in therapy.

The purpose of the present study was to examine therapist actions that predict the bond and to determine how these actions work with the bond to create the benefits of therapy ${ }^{1}$. In this study, we thus examine the relationships between therapist actions, the bond, and outcome, as indicated by symptoms, in two treatments, cognitive therapy (CT) and short-term dynamic psychotherapy (STDP), for cluster C patients. Given previous research that indicates that the bond was not predictive of outcome in CT (Webb et al., 2011), we were interested to determine whether the bond worked differently in a dynamic therapy than it did in a CT. The cluster $\mathrm{C}$ patient group is an interesting group on which to study these phenomena, as a defining feature of the diagnosis is the patient's difficulty with experiencing and expressing affect and forming adaptive close interpersonal relationships.

\section{Method}

\section{Data Material}

Psychotherapy sessions from a previously conducted randomized clinical trial (RCT) that compared CT and STDP for cluster C patients were used in the study (see Svartberg, Stiles \& Seltzer, 2004 for more details). In this study, the patient groups showed significant improvement on all measures during treatment, and there were no group differences in outcomes on any measures (Svartberg et al., 2004).

\section{Patients}

There were 50 patients in this RCT; 25 in each treatment. All patients met criteria for one or more Diagnostic and Statistical Manual of Mental Disorders-III-R cluster C personality disorder, and did not meet criteria for any other axis II disorder. Additional exclusion criteria were current or past psychotic disorder, current substance abuse or dependence, current eating disorder, organic brain disorder and other serious physical illness, active suicidal behavior, refusal to discontinue other active treatments,

\footnotetext{
${ }^{1}$ Although it would be interesting to examine these relations in all three components of the alliance, the data collected in this clinical trial only contained measurement of the bond.
} 
and refusal to have therapy sessions videotaped. There were no significant differences in the measured patient characteristics between the treatment conditions. Due to one patient missing alliance data and poor quality of video recordings for three patients, 46 patients of the 50 patients in the RCT were included in the present analysis; 23 in each condition. See Table 1 for demographic details.

\section{Therapists and Treatment}

The CT and STDP treatments were carried out in accordance with treatment manuals (Beck \& Freeman, 1990; McCullough Vaillant, 1997, respectively). Half of the patients received 40 weekly sessions of CT, whereas the other half received the same amount of STDP. All sessions lasted 50 minutes and were videotaped. Treatment adherence and competence were monitored using video-based group supervision. The clinical supervisor gave adequate feedback on how to improve the treatment in accordance with the treatment manual. All therapists treated at least one patient as a training exercise before treating patients who were enrolled in the study. No cases were excluded as a result of low treatment competence or adherence (Svartberg et al., 2004).

Treatment integrity was assessed with the inventory of therapeutic strategies, plus assessment of agenda setting and homework. The two raters were reliable $(r>.65$; range $=0.65-0.83 ; M=$ 0.73 ), and two-tailed tests showed the two treatments to differ in emphasis on supportive strategies $(t=2.2, d f=48, p<.02)$,

Table 1

Demographic and Clinical Characteristics of Patients Who Received Either CT or STDP

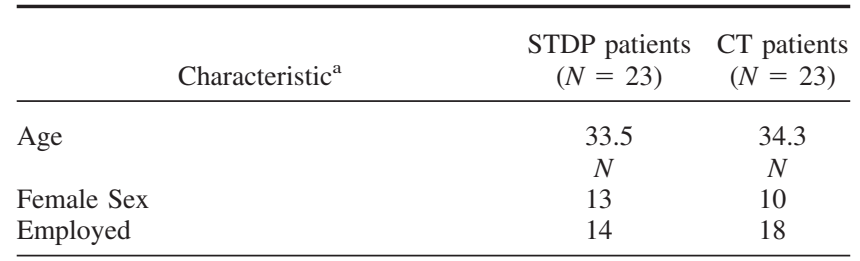

Axis I diagnosis

Major Depression, Current episode

Major Depression, Previous episode

Dysthymia

Panic disorder ${ }^{\mathrm{b}}$

Agoraphobia $^{\mathrm{C}}$

Social phobia

Obsessive-compulsive disorder

Generalized anxiety disorder

Somatization disorder

No diagnosis

\begin{tabular}{rr}
6 & 11 \\
8 & 10 \\
7 & 2 \\
2 & 2 \\
2 & 2 \\
7 & 12 \\
3 & 4 \\
12 & 14 \\
1 & 3 \\
2 & 1 \\
\hline
\end{tabular}

Axis II disorder ${ }^{\mathrm{d}}$

Avoidant personality disorder

Obsessive-compulsive personality disorder

Dependent personality disorder

Passive-aggressive personality disorder

Self defeating personality disorder

More than one personality disorder

$\begin{array}{rr}15 & 15 \\ 8 & 8 \\ 4 & 5 \\ 1 & 2 \\ 1 & 2 \\ 4 & 7\end{array}$

a Treatment groups did not differ significantly on any characteristic. ${ }^{\mathrm{b}}$ With or without agoraphobia. ${ }^{\mathrm{c}}$ Without history of panic disorder. ${ }^{\mathrm{d}}$ Patients may have received more than one axis II disorder. agenda setting $(t=9.9, d f=48, p<.0001)$, and homework $(t=$ 5.6, $d=48, p<.0001)$ (CT emphasized more), defense work $(t=$ $4.0, d f=48, p<.001)$, and transference work $(t=3.33, d f=48$, $p=.002$ ) (STDP emphasized more). For work enhancing strategies, the emphasis was equally strong for the two treatments $(t=$ $0.03, d f=48, p=.50$ ) (Svartberg et al., 2004).

The CT therapists were six clinical psychologists with a mean of 11.2 years of clinical experience $(S D=4.3)$. All CT therapists were trained in the CT model and received supervision and seminars from CT experts such as J. Beck, A. Freeman, and J. Young (Svartberg et al., 2004). The STDP therapists were three psychiatrists and five clinical psychologists with a mean of 9.2 years of clinical experience $(S D=3.6)$. All STDP therapists were trained in the STDP model and received supervision and seminars from $\mathrm{L}$. McCullough (Svartberg et al., 2004).

\section{Instruments}

The Helping Alliance Questionnaire. The Helping Alliance Questionnaire (HAQ; Luborsky, Crits-Cristoph, Alexander, Margolis, \& Cohen, 1983) was designed to be a pantheoretical measure of the therapeutic alliance. The patients rated the instrument after Session 4. The HAQ consists of 11 questions each rated on a scale with the following scale points: -3 (strongly disagree), -2 (disagree), -1(slightly disagree), 1 (slightly agree), 2 (agree), and 3 (strongly agree). A total score is calculated, in which a higher score is indicative of a better alliance. The HAQ has been found to be both reliable and related to outcome (Horvath \& Symmonds, 1991; Martin, Garske, \& Davies, 2000).

The HAQ has been found to include questions that are reflective of early symptom improvement, rather than the alliance, and has appeared in a revised version where these items are excluded (Luborsky, 1996). Using only items 6, 7, 8, 9, 10, the measure used in this study therefore consists only of items considered to represent the therapeutic bond (Luborsky et al., 1996; Cronbach's alpha $=.90$ in the present study). The bond, as discussed earlier, is a central and defining feature of any alliance, and, as such, only the items that addressed the bond were included in the analysis.

Psychotherapy Process Q-Sort. Psychotherapy Process Q-Sort (PQS) (Jones, 1985) is an observer-rated broad measure of the psychotherapy process. The PQS was developed pantheoretically to assess therapist actions valued across therapies, making it especially useful for comparing the process of different therapies (Jones, Hall, \& Parke, 1991; Lambert \& Hill, 1994). The PQS contains 100 clinically relevant items that describe an entire psychotherapy session. Items refer to specific actions, behaviors, and statements by both patient and therapist. The scoring involves the Q-sort method and thus yields ipsative scores. Specifically, each of the 100 items is given a score from 1 (uncharacteristic of the session) to 9 (very characteristic of the session). In PQS, each score can only be given a fixed amount of times for every session (only 5 items can be given a 1 and a 9, only 8 items can be given a 2 and 8 etc.). This requires the judges to make multiple evaluations among items and thereby avoids halo effects and response sets (Block, 1961) and yields a normal distribution.

Reliability and validity of the PQS has been shown across a number of studies and treatment samples (Jones et al., 1991). 
Interrater reliability across all items has repeatedly been shown to be satisfactory (alpha range from 0.83 to 0.89 ). Computing interrater reliability for single items has also given satisfactory results (alpha range from 0.50 to 0.95 ). There is also considerable evidence for the construct and discriminant validity of PQS (Jones, Cumming, \& Horowitz, 1988, 1991; Jones, Krupnick, \& Kerig, 1987; Jones \& Pulos, 1993; Lingiardi, Colli, Gentile, \& Tanzilli, 2011; see also Ablon \& Jones, 1999). For the purpose of this study, the mean level of PQS items was calculated over the first four sessions of therapy (i.e., before the alliance was assessed), making a single mean score for each patient.

In this study, the PQS was rated by 25 students, all of whom were enrolled in a clinical master's degree program in psychology at one of three different universities in Norway. They had studied from six months to four years and had little or no clinical experience. The raters attended a 2-day seminar, which included theoretical introduction and practical exercises and which was conducted by two expert raters. After the seminar, the raters practiced on their own using stimulus videotapes that had already been rated by experts. They then sent their scores to expert raters, who provided feedback on the raters' performance. To determine a rater's reliability, a Pearson's $r$ was calculated as a correlation between the rater's score and the expert score. To qualify for the study, raters had to rate five sessions with a Pearson's $r$ of at least .5. Student raters used a mean of 17 hours (range, 10-26) to achieve reliability on PQS. From an initial pool of 50 raters, 25 reached the criterion reliability level and were willing to participate in the study. Based on sample of ratings, the scores produced by the raters were dependable, as determined by a generalizability analysis (G-coefficient of 0.97; see Ulvenes, Berggraf, Wampold, Hoffart, \& McCullough, 2012, for more details).

One purpose of the article was to investigate therapist actions that promote the therapeutic bond. The $38 \mathrm{PQS}$ items that focused on therapist actions were therefore selected from the 100 PQS items. The correlations between the items and the bond derived from the HAQ were examined. Of these items, four were significantly correlated with HAQ Bond at the .05 level, namely the following:

1. Therapist draws attention to patient's nonverbal behavior, for example, body posture, gestures, tone of voice $(n=46, d f=44$, $\mathrm{r}=-0.516, p=.002$ )

2. Therapist is sensitive to the patient's feelings, attuned to the patient; empathic $(n=46, d f=44, \mathrm{r}=-.402, p=.017)$

3. Therapist is distant, aloof (vs. responsive and affectively involved) $(n=46, d f=44, r=.384, p=.023)$

4. Therapist comments on changes in patient's mood or affect that occur during the hour $(n=46, d f=44, \mathrm{r}=-.377, p=.026$ )

All these items focused on the therapist either paying attention to affect, or emotional retreat or withdrawal, as illustrated in Table 2. The rating scale for items 1,2 , and 4 were reversed, so that a higher score on these PQS items were positively correlated to the bond. As a result, a higher score on these PQS items reflected avoidance of affect; that is to say, the more affect was avoided, the better the bond. Because the items were scored to indicate avoidance of affect, the average of the four items composed a scale referred to as PQS Affective Avoidance (PQS-AA). ${ }^{2}$ The Cronbach's alpha for the four-item scale for the 46 patients was 0.70 .

Symptom Check List 90-R. Symptom Check List 90-R (SCL90) is a broad measure of symptom distress relevant for psychotherapy. It is a self-report instrument, and produces nine subscales, along with a Global Severity Index (GSI, Derogatis, 1983, 1994). In the analyses for this article, the GSI scores at start and termination of therapy were used. The GSI is often used as a general symptom outcome measure in clinical trials (Derogatis \& Savitz, 2000). The mean GSI for a normal population $(n=974)$ is $0.31(S D=0.31)$. Derogatis (1983) did not report Cronbach's alpha for the GSI, but across two studies, the subscales from which the GSI is derived had a Cronbach's alpha ranging from 0.77 to 0.90. A more recent validation study found a Cronbach's alpha for the GSI of 0.94 for a nonclinical sample of 1006 persons (Schmitz, Hartkamp, Kiuse, Franke, Reister, \& Tress, 2000). In the following analysis in this study, the GSI was reversed, so that a higher score indicate greater symptom relief (i.e., higher scores reflected more positive outcomes and consequently higher correlations with SCL-90 scored in this way indicate that the other variable is positively related to outcome).

Analysis. The analysis involved a number of regression analyses. The first model predicted the SCL90 from the bond, accounting for the pretest. We expected a positive relationship between bond and reduction in symptoms. In the second regression, we predicted the bond from the PQS-AA and we knew this relationship would be positive and significant, as the PQS-AA items were selected because of their significant relationship with the bond. The third model predicted the SCL90 from the PQS-AA, accounting for the pretest. We were interested in the degree to which the PQS-AA was related to symptom reduction. The final model predicted the SCL90, accounting for the pretest, from both the bond and the PQS-AA in order to determine how these two variables work together to produce outcome. Because of the exploratory nature of the study, we used two-tailed tests with a liberal alpha level of 0.10 . We also tested to see whether the models for the two treatments differed.

\section{Results}

The means and standard deviations for each of the instruments used in the study are presented in Table 3, and pairwise correlations for residual gain score for SCL90, PQS-AA, and bond are presented in Table 4.

Because the alliance is thought to operate similarly across different types of therapy and because there were no difference in changes in symptoms between CT and STDP, the first analysis included the total sample, notwithstanding Webb et al.'s (2011) suggestion that the alliance may work differently for CT than for other treatments. However, as will be seen, there were indeed differences between the two treatments and those results are presented subsequently.

\footnotetext{
${ }^{2}$ For one session, a therapist might receive a score of 7 for drawing attention to patient's non-verbal behavior, a score of 6 for being sensitive to the patient's feelings, attuned to the patient; empathic, a 2 for being distant and aloof, and 5 for commenting on changes in the patients mood or affect. Reversion was done by the formula: reverse score $(\mathrm{x})=((\operatorname{Max} \mathrm{x})$ $+1)-x$. After reversion the mean score for the four items would be $(9+1-7)+(9+1-6)+2+(9+1-5) / 4=2.8$. This is a low score, indicating that affect avoidance was not dominant in the session. A mean score for the first four sessions was computed to create the PQS-AA.
} 
Table 2

Examples of Therapist Behavior From the PQS-AA

PQs-AA item description

Therapist draws attention to patient's nonverbal behavior, e.g. body posture, gestures, tone of voice

Therapist is sensitive to the patient's feelings, attuned to the patient; empathic

Therapist is distant, aloof (vs. responsive and affectively involved)

Therapist comments on changes in patient's mood or affect that occur during the hour
Example of therapist behavior

Do you notice how your voice becomes softer, and it is hard for you to meet my eyes when we talk about this? Why do you think that is?

There seems to be a lot of feelings attached to this for you. It seems really hard, but I am here with you, and these are only feelings, you know.

So there is a lot of feeling about what happened after last session. Is there anything else we should talk about?

Did you notice what just happened? We were talking about your day, and you were sitting upright, looking at me. But the moment we started talking about you standing up to your boss, you seem anxious, you have your neck bent down as in shame, and your voice is low. What do you think happened here?

\section{Total Sample}

The results of the regression analyses examining the relationship of the bond, therapist actions related to affective avoidance (i.e., PQS-AA), and change in symptoms (i.e. SCL90) are presented in Table 5. As expected, the bond was positively related to a reduction in symptoms (i.e., in a regression with the SCL90-Post test as the dependent variable and the SCL90 at pretest as an independent variable) (Std Beta $=0.233, p=$ .059). Also, as was surely the case given the way in which the PQS items were selected, PQS-AA was positively related to the bond (Std Beta $=0.471, p=.004$ ); that is, the more the therapist avoided eliciting or commenting on affective material, the higher the patient's rating of the bond.

As discussed previously, certain therapist actions are associated with the alliance and (here the bond) and does not necessarily imply that these therapist actions are predictive of outcome. Consequently, the next analysis examined the association of PQS-AA and reduction in symptoms. For this sample, PQS-AA was not significantly related to SCL90 (after accounting for pretest, Std Beta $=0.081, p=.591)$. That is to say, although certain therapist actions (viz., avoiding affect) were related to the bond, they were not related to outcome. This suggests that PQS-AA was either related to an aspect of the bond that is not relevant to outcome, or the PQS-AA actually was related to a part of the bond that was not therapeutic. The latter option would represent an instance of suppression (Cohen \& Cohen, 1983; Conger, 1974; MacKinnon, Krull \& Lockwood,

Table 3

Means and Standard Deviations for Instruments Used in Analysis, Combined and by Treatment

\begin{tabular}{|c|c|c|c|c|c|c|}
\hline \multirow[b]{2}{*}{ Measure } & \multicolumn{2}{|c|}{$\begin{array}{l}\text { Total sample } \\
\quad(n=46)\end{array}$} & \multicolumn{2}{|c|}{$\begin{array}{c}\text { STDP } \\
(n=23)\end{array}$} & \multicolumn{2}{|c|}{$\begin{array}{c}\mathrm{CT} \\
(n=23)\end{array}$} \\
\hline & Mean & $S D$ & Mean & $S D$ & Mean & $S D$ \\
\hline SCL90 Pre & 3.79 & 0.66 & 3.87 & 0.61 & 3.71 & 0.71 \\
\hline SCL90 Post & 4.2 & 0.57 & 4.24 & 0.50 & 4.15 & 0.64 \\
\hline PQS-AA & 3.96 & 0.72 & 3.92 & 0.83 & 3.99 & 0.58 \\
\hline HĀQ & 9.44 & 4.90 & 9.35 & 3.14 & 9.52 & 6.26 \\
\hline
\end{tabular}

Note. Because of reverse scoring of the SCL, a higher score indicates less symptom distress. For PQS-AA, a higher score means the therapist is more avoidant of affect. For HAQ, a higher score is indicative of a stronger bond.
2000; Tzelgov \& Henik, 1991), which refers to "a variable which increases the predictive validity of another variable (or set of variables) by its inclusion in a regression equation" (emphasis added, Conger, 1974, pp. 36-37).

The final step of the analysis therefore included both PQS-AA and bond in the analysis, as shown in Table 5. In this analysis, it is clear that PQS-AA indeed does suppress the importance of the bond, as the coefficient for the bond increased when PQS-AA was included in the model (i.e., the Std Beta for bond increased from 0.233 to 0.327 ). That is, focusing on affect reduces the bond, but not the aspects of the bond that lead to better outcomes.

These results are not consistent with Webb et al. (2011), who found that the bond was not related to a reduction in symptoms for CT. Consequently, we were interested to know whether the results were applicable to both treatments. To see if there were treatment differences, two general linear models using maximum likelihood estimators were assessed. The first model included SCL90 at the two time points, the PQS-AA and the bond. The second model included all the previous variables, plus treatment condition. The difference between the log likelihoods for model fit was significantly greater than the critical value (viz., 22.276 compared with a chi square distribution with $1 d f, p<.001$, indicating the model for CT was different from the model for STDP, and therefore we investigated each treatment separately.

Table 4

Pair-Wise Correlation for SCL90 Residual Gain Score, PQS, and Bond

\begin{tabular}{lccc}
\hline & SCL 90 residual & PQS-AA & Bond \\
\hline SCL 90 Residual & & & \\
$\quad$ Total sample & 1.0 & .091 & .274 \\
STDP & 1.0 & -.246 & .135 \\
CT & 1.0 & $.569^{*}$ & .340 \\
PQS-AA & & & \\
$\quad$ Total sample & .091 & 1.0 & $.456^{* *}$ \\
STDP & -.246 & 1.0 & $.463^{*}$ \\
CT & $.569^{*}$ & 1.0 & $.479^{*}$ \\
Bond & & & \\
Total & .274 & $.456^{* *}$ & 1.0 \\
STDP & .135 & $.463^{*}$ & 1.0 \\
CT & .340 & $.479^{*}$ & 1.0 \\
\hline
\end{tabular}

* Two-tailed test, significant at the 0.05 level. ${ }^{* *}$ Two-tailed test, significant at the 0.01 level. 
Table 5

Regression Analyses For Bond, PQS-AA, and SCL90, by Treatment

\begin{tabular}{|c|c|c|c|c|c|c|c|c|c|c|c|c|c|}
\hline \multirow[b]{2}{*}{ Dependent } & \multirow[b]{2}{*}{ Independent } & \multicolumn{4}{|c|}{ Total sample $(n=46)$} & \multicolumn{4}{|c|}{$\operatorname{STDP}(n=23)$} & \multicolumn{4}{|c|}{$\mathrm{CT}(n=23)$} \\
\hline & & Std Beta & $\beta$ & $S E_{\beta}$ & $p$ & Std Beta & $\beta$ & $S E_{\beta}$ & $p$ & Std Beta & $\beta$ & $S E_{\beta}$ & $p$ \\
\hline \multirow[t]{2}{*}{ SCL90-Post } & SCL90 Pre & 0.617 & 0.520 & 0.103 & .000 & 0.558 & 0.451 & 0.558 & .006 & 0.644 & 0.577 & 0.153 & .001 \\
\hline & Bond & 0.233 & 0.033 & 0.017 & .059 & 0.119 & 0.021 & 0.032 & .525 & 0.303 & 0.039 & 0.022 & .091 \\
\hline Bond & PQS-AA & 0.471 & 1.973 & 0.644 & .004 & 0.480 & 1.657 & 0.734 & .037 & 0.498 & 2.402 & 1.119 & .050 \\
\hline \multirow[t]{2}{*}{ SCL90-Post } & SCL90 Pre & 0.515 & 0.430 & 0.124 & .001 & 0.677 & 0.602 & 0.154 & .001 & 0.303 & 0.239 & 0.162 & .164 \\
\hline & PQS-AA* & 0.081 & 0.057 & 0.105 & .591 & -0.185 & -0.116 & 0.109 & .302 & 0.582 & 0.518 & 0.183 & .014 \\
\hline \multirow[t]{3}{*}{ SCL90-Post } & SCL90 Pre & 0.512 & 0.426 & 0.121 & .001 & 0.638 & 0.563 & 0.147 & .002 & 0.305 & 0.241 & 0.166 & .173 \\
\hline & PQS-AA* & -0.083 & -0.059 & 0.117 & .619 & -0.379 & -0.239 & 0.120 & .065 & 0.507 & 0.452 & 0.216 & .058 \\
\hline & Bond & 0.327 & 0.056 & 0.028 & .055 & 0.357 & 0.065 & 0.035 & .081 & 0.150 & 0.028 & 0.045 & .547 \\
\hline
\end{tabular}

Note. The difference between the log likelihoods for model fit for a model with treatment versus a model without treatment was significantly greater than the critical value (viz., 22.276 compared to a chi square distribution with $1 \mathrm{df}, p<.001$, indicating the model for CT was different from the model for STDP. * Because of reverse scoring of PQS-AA and SCL, negative values of PQS-AA (therapist being affect avoidant) leads to lower values on SCL (patients reporting more distress).

\section{Short-Term Dynamic Psychotherapy}

The results for STDP parallel those of the total sample, except that the suppression effect was more pronounced. By itself, the bond was not associated with a reduction in symptoms (Std Beta $=$ $0.119, p=.525)$, which would be a surprising result. As in the total sample, PQS-AA was unrelated to outcome (Std Beta = $-0.185, p=.302$ ), although the direction was opposite to that of the total sample. When both the PQS-AA and bond are in the model, the bond is now a significant predictor of the reduction in symptoms (Std Beta $=0.357, p=.081$ ). This is the classic suppressor in that bond was only significant when the portion related to affect was removed. Keeping in mind that if variable $X$ suppresses $\mathrm{Y}$, then $\mathrm{Y}$ also suppresses $\mathrm{X}$ (Cohen \& Cohen, 1983), we see that bond has suppressed PQS-AA as PQS-AA is now associated with a reduction in symptoms, that is less avoidance of affect predicted symptom improvement (Std Beta $=-0.379, p=.065$ ). Said in another way, in STDP, in the context of the bond, a focus on affect is related to a reduction in symptoms, even if such actions decrease the bond.

\section{Cognitive Therapy}

The results for CT are quite different from those of STDP. Although bond was not related to a reduction of symptoms in STDP (without considering PQS-AA), it was for CT (Std Beta $=0.303, p .=.091)$. However, when both PQS-AA and bond are considered, a different pattern emerges. PQS-AA was now positively related to a reduction in symptoms (Std Beta $=$ 0.507, $p=.058$ ); that is, in the context of the bond, avoiding affective material in CT led to better outcomes, which is the opposite of what was found in STDP. Interestingly, in the context of the PQS-AA, the bond is no longer associated with a reduction in symptoms (Std Beta $=0.150, p=.547)$.

\section{Discussion}

The results of the present study paint a complex picture of therapist actions that create a bond and how the bond is then related to outcomes in the psychotherapy of cluster $\mathrm{C}$ personality disorder patients. First, we found that the relationship among therapist actions, bond, and outcomes in psychotherapy differs depending on the therapeutic approach. Therapist avoidance of affect was found to be positively related to formation of the bond, as rated by the patient, in both STDP and CT. That is, patients in this study found the focus on affect to be problematic in terms of feeling bonded to their therapist. However, the avoidance of affect (or alternatively, the focus on affect) functioned very differently in the two treatments. In STDP, although a focus on affect detracted from the bond, this focus resulted in a reduction of symptoms, and, as well, the part of the bond not related to a focus on affect was predictive of outcome. However, in CT, the portion of the bond not related to a focus on affect was unrelated to outcome and a therapist focus on affect was counterproductive.

The differences between STDP and CT found in this study were consistent with theoretical conjectures (Bordin, 1979, 1980, 1994; Hatcher \& Barends, 2006; Wampold \& Budge, 2012) and empirical findings (Webb et al., 2011, see also Blagys \& Hilsenroth, 2000 for a review of empirical differences between STDP and CT in affect focus). That is to say, the bond, and most likely the alliance more generally, may well function differently in different therapies, particularly with cluster C patients. So, reference to the alliance as a common factor may be misleading in the sense that although the importance of the alliance may be common, the manner in which it interacts with the specific treatment to achieve benefits may not be common (see, e.g., Hoffart, Borge, Sexton, Clark, \& Wampold, 2012). In Tables 6 and 7 transcripts of an interaction between an STDP therapist and a patient, and a CT therapist and a patient are presented. The transcripts are intended to describe all four therapist actions included in this study. To achieve this, the transcripts were developed from typical interactions in the two treatment orientations, at Session 4.

The analysis for STDP shows that the bond predicts outcome, and that the bond is also related to the therapist being distant or avoiding affect, but that the therapist being distant and avoidant of affective material is not predictive of the outcome. Affect phobia therapy, the short-term dynamic therapy used in this RCT, views psychopathology as a consequence of a conflict between activating and inhibitory feelings. This conflict blocks the patients' adaptive 
Table 6

Transcript ${ }^{a}$ of a Part of Session Four in Psychodynamic Therapy, Illustrating Therapist Actions Investigated in the Current Study

\begin{tabular}{ll}
\hline & Verbatim material \\
\hline Therapist & Last session we worked a lot with the feelings you are struggling with. \\
& How have you been, we were working hard? How does it feel being \\
here, what are your expectations for today? \\
It's been tough, I've been feeling sad. I think this is important for me, \\
but it costs a lot. It's important to do this, but I'm not looking \\
forward to the session. I don't want to fall as deep as I did last \\
time. I have things I need to get done, I have responsibilities. It is \\
hard. (Looks away, stiff and unmoving body, voice somewhat \\
trembling) \\
It sounds tough. It is something important in what we do, but it costs a \\
lot. (Moves body forward, low and soothing voice) \\
I'm afraid I won't get back up again. I'm afraid to go deep into my \\
mess. \\
Therapist \\
What's hard about going deep in your mess? \\
It's hard to tolerate the feelings. It's like when I was 16 and no one \\
was there for me. I feel the same all over again. I feel locked in and \\
Patient \\
I can't relate to people. (Looks down and away) \\
That you are saying is important. You feel afraid and locked up, and \\
the feelings come back to you again. There was a wave of sadness \\
in your face just then. Will you be alone with the feeling, or will \\
someone be there with you? (Searches for eye-contact, voice still \\
soft and low) \\
I won't be alone in this session ... But when the door closes I feel \\
lost. (Faces therapist) \\
What do you feel in your body when you say that you are alone and \\
lost? (Maintains eye contact and mirrors the patients body posture) \\
It sinks into me. In my stomach. It's in knots. And like some heavy \\
weights on my shoulders. (Sinks down in the chair, diverts eye \\
contact again) \\
Patient
\end{tabular}

Patient

Therapist

Patient

Therapist

Patient

Therapist

Patient

Therapist

Patient

Therapist

Patient

Therapist

Patient

Therapist

Patient

Therapist

Patient

Therapist

Patient
Creepy, uncomfortable feeling. And a heavy weight on my shoulders. That sounds exhausting. For how long have you felt like this?

16 (Empathic voice)

What do you feel like you need?

Weights—-stomach-alone...

What do you need, what do you wish for? (Modulates voice, leans body towards patient)

Hard ... (Looks away, upper body leaning forward)

What do you need? (Looks up, leans back in chair)

I know what I don't need . .

That's safer.

That question makes me feel insecure. I wish someone was there, I don't feel safe with other people. (Looks at therapist)

It has been tough opening up here.

All of a sudden people can be gone. (Soft voice)

And maybe it has been like that for you. Letting people get close has not been a good experience for you. You are in a dilemma here. (Soft voice)

That's why it's so hard to get into this. (Eye-contact with therapist)

There's a lot that is scary about this. I want to go back to what you need or wish for?

Accept me like I am. [Short pause]

How would that be?

Don't have to fake, pull my self together.

Perform?

How is it to feel that it is good to be accepted?

Relief. The thought makes me happy. It would have been nice. (Brief smile)
Therapist is sensitive to the patient's feelings, attuned and affectively involved.

Therapist searches for feeling.

Therapist draws attention to the patient's non-verbal behavior and comments on change in mood. Therapist is sensitive to the patient's feelings and affectively involved. Therapist is exposing for affect.

Therapist encourages affect experiencing. Therapist is attuned and empathic.

Validates the patients feelings, is attuned and responsive. Draws attention to non-verbal behavior.

Therapist is attuned and empathic.

Therapist is attuned and empathic. Therapist is exposing for feeling.

Therapist is attuned, empathic, affectively involved and responsive.

Therapist validates the patient's experience.

Therapist validates the patient's experience.

Therapist is attuned and empathic.

Therapist is attuned and empathic. Continues to expose for affect.

Continues to expose for affect.

Continues to expose for affect. 
Table 6 (continued)

Verbatim material

\begin{tabular}{|c|c|}
\hline Therapist & $\begin{array}{l}\text { And now you were able to feel a little of it also, and you felt that it } \\
\text { was good. You did it, and it felt good. } \\
\text { How is that for you? }\end{array}$ \\
\hline Patient & I get moved. (Brief smile and quickly tears up) \\
\hline Therapist & $\begin{array}{l}\text { This was important for you. Breathe a little. How does it feel with me } \\
\text { now, still a bit scary? }\end{array}$ \\
\hline Patient & $\begin{array}{l}\text { Not as scary now, I liked the questions on what I needed. It felt easier } \\
\text { when you helped me. (Faces therapist) }\end{array}$ \\
\hline Therapist & $\begin{array}{l}\text { I want to challenge you some more. What do you think I wish for } \\
\text { you? }\end{array}$ \\
\hline Patient & That's hard. You hope that I get better? \\
\hline Therapist & What do I feel for you? That's hard to think about. \\
\hline & $\begin{array}{l}\text { Alone, weight on your shoulders, afraid. What do you think I feel for } \\
\text { you? (Leans forward towards patient, soft voice) }\end{array}$ \\
\hline Patient & $\begin{array}{l}\text { You want me to feel good about myself. But you think that it's a long } \\
\text { way before I get there. (Faces therapist but diverts eye-contact) }\end{array}$ \\
\hline Therapist & $\begin{array}{l}\text { But you think you're going to need a lot of time. What does it feel } \\
\text { like that I have those feelings towards you? }\end{array}$ \\
\hline Patient & [Silent] (Looks down and away) \\
\hline Therapist & Did it get hard for you when we came this close? \\
\hline
\end{tabular}

Comment

Comments on changes in patient's mood, is
empathic, and continues exposure.

Therapist is responsive and affectively involved.

Therapist exposes for affect.

Therapist is empathic and responsive. Continues to expose for affect.

Therapist is empathic and responsive. Continues to expose for affect.

Therapist is empathic and responsive.

${ }^{\text {a }}$ In order to include all therapist actions investigated, the transcript is developed from typical interactions observed in short-term dynamic therapy at session 4 .

expression of affect and can be thought of as a phobia for feeling the conflicted affect. Affects are treated as primary motivational forces in the treatment (Tomkins, 1962, 1963, 1991, 1992). Affect phobia treatment capitalizes on understanding the complex dynamic between affective motivational forces and exposing the patient to the experience of the conflicted feeling. This exposure process leads to desensitizing the activating affect, allowing it to be used more adaptively (see, e.g., McCullough-Vaillant, 1997; McCullough et al., 2004). The primacy of affect focus in psychodynamic therapies has also been investigated in several studies, and it appears that in these treatments, affective work leads to positive outcomes (see, e.g., Diener, Hilsenroth \& Weinberger, 2007 for a meta-analysis on affect in psychodynamic psychotherapy; as well as Diener \& Hilsenroth, 2009 and McCullough \& Magill, 2009).

Because of the emphasis on affect as a change mechanism in the dynamic treatment, it is logical that the therapist avoidance of affect was not productive of outcome. This can be interpreted as the therapist avoiding affect may help the patient like the therapist or therapy better, but it does not help the patient get better. The puzzling part of the findings is that this kind of therapist behavior is predictive of the bond and the bond is predictive of outcome. This has two central implications: The bond is important in STDP, and the bond has to form despite the therapist focusing on affect. The first discussion of the alliance construct is often traced back to Freud (see, e.g., Horvath, 2001), who noted the apparent paradox that patients remained in therapy despite the often painful and troublesome feelings they had to experience with the therapist. Another way to understand the findings is that the bond might consist of several parts, one that is predicted by the therapist avoidance of affect (i.e., avoiding what is needed in STDP), and at least one part that is not. Other therapist interventions, not captured by the therapist behaviors included in the PQS-AA, might be predictive of both the outcome and of other aspects of the bond.
In the segment of STDP presented in Table 6, the short-term dynamic therapist is investigating and exposing the patient to feelings. The segment starts out with the patient being reluctant to go into affect. The therapist focuses on feelings of closeness and compassion toward the self, and does so in a very attuned and empathic way. She is affectively involved and stays close to the patient's experiences in the session. The therapist is both drawing attention to nonverbal behavior and comments on changes in mood that occur in the session. Still, the bond in the dyad is strong. The therapist has managed to create a bond despite the focus on affect and, therefore, is able to do work that has been found to be associated with a favorable outcome (see, e.g., Diener, Hilsenroth \& Weinberger, 2007). Blagys and Hilsenroth $(2000,2002)$ also identified several therapist behaviors that separate dynamic therapy from CT. Among these were a focus on affect and expression of emotions, and exploration of the patient's attempts to avoid topics or divert from activities that promoted therapy progress. Related to the importance of our findings here, in a study of therapist actions and treatment outcome in depression, Hilsenroth, Ackerman, Blagys, Baity, and Mooney (2003) identified two specific dynamic interventions, "the therapist encourages the patient to experience and express feelings in the session" and "the therapist addresses the patient's avoidance of important topics and shifts in mood" that were significantly related to symptom improvement in depression.

The results related to $\mathrm{CT}$ are complex but appear to be consistent with previous research. CT focuses on cognitions and attributions and therefore a focus on affective states could, as the present results suggest, interfere with the specific ingredients of CT. At first glance, it appears that the bond is important for CT, a result contradictory to Webb et al. (2011); however, the relationship between the bond and reduction in symptoms may have been an artifact of the focus on affect. In CT, at least in this study, it appears that a focus on affect by the therapist creates a weaker 
Table 7

Transcript ${ }^{a}$ of a Part of Session Four in Cognitive Therapy, Illustrating Therapist Actions Investigated in the Current Study

\begin{tabular}{|c|c|c|}
\hline & Verbatim Material & Comment \\
\hline Therapist & Last time we ended after we discussed how you typically think about yourself. & \\
\hline Patient & $\begin{array}{l}\text { Yes, I think of my self as weak, I can't do anything, I feel like withdrawing. } \\
\text { (Patient looks down and away from therapist). }\end{array}$ & Mentions a core belief \\
\hline Therapist & So what are you thinking about yourself then? & Therapist investigates thoughts about belief \\
\hline Patient & $\begin{array}{l}\text { I'm not good enough, I can't do anything, I'm not smart enough. I can't } \\
\text { express myself, I'm not social. I can't concentrate, my head is just one big } \\
\text { buzz. (Patient continues to look away, but is not looking down anymore) }\end{array}$ & \\
\hline Therapist & $\begin{array}{l}\text { It takes control over you. Now, you've said a few things, but how do you } \\
\text { feel? }\end{array}$ & $\begin{array}{l}\text { Validates the patient's experiences. Asks } \\
\text { for feelings. }\end{array}$ \\
\hline Patient & $\begin{array}{l}\text { Fatigued and powerless. Sad. Everyone else can do this, I get paralyzed. } \\
\text { (Patient looks sad, lowers head again, voice gets lower) }\end{array}$ & \\
\hline Therapist & $\begin{array}{l}\text { You feel sad, and compare yourself to other people. If we look closer at what } \\
\text { you said, how much fatigue and powerlessness do you feel for each of these } \\
\text { things on a 1-100 scale? } \\
\text { Lets start with "I'm weak". How much do you feel then? } \\
\text { (Therapist modulates voice for a short while, resembles that of patient) }\end{array}$ & $\begin{array}{l}\text { Sums up the patients feelings. Asks for } \\
\text { more information, but does not go into } \\
\text { deep emotions. }\end{array}$ \\
\hline Patient & $\begin{array}{l}\text { It's a very general thing, in some situations I'm weak, ... } \\
\text { (Patient looks up again, more animated than earlier) }\end{array}$ & \\
\hline Therapist & $\begin{array}{l}\text { (Interrupts) It gets tricky to say, but how about right now? How much do you } \\
\text { feel? } \\
\text { (Therapist moves upper body towards patient, is pointing with his hand } \\
\text { towards patient) }\end{array}$ & $\begin{array}{l}\text { Refocuses and challenges the patient to } \\
\text { give more information on emotions. Is } \\
\text { investigating descriptions of feelings, } \\
\text { does not go into experiencing feelings. }\end{array}$ \\
\hline Patient & $\begin{array}{l}\text { It's about } 70-80 . \\
\text { (Patient keeps looking up, has eye-contact with therapist for a short while. } \\
\text { Patient seems more at ease). }\end{array}$ & \\
\hline Therapist & $\begin{array}{l}\text { If you think about "I'm not good enough" how much from } 1-100 \text { ? } \\
\text { (Therapist is still facing patient, and is taking notes in between looking at the } \\
\text { patient) }\end{array}$ & $\begin{array}{l}\text { Gets more descriptions, continues to follow } \\
\text { the affect theme on a cognitive level. }\end{array}$ \\
\hline Patient & $\begin{array}{l}\text { Frightening, lots of powerlessness, close to } 90 \text {. It's hard to put on a scale, the } \\
\text { feelings become scary. } \\
\text { (Patient looks momentarily down and away, before looking up again) }\end{array}$ & \\
\hline Therapist & $\begin{array}{l}\text { Strong feelings. } \\
\text { How much powerlessness do you feel with "I can't do it"? } \\
\text { (Still facing patient and taking notes) }\end{array}$ & $\begin{array}{l}\text { Validates patients experience, continues to } \\
\text { investigate descriptions of feelings. }\end{array}$ \\
\hline Patient & $\begin{array}{l}\text { We are touching on } 90 \text { to } 100 \text {. This locks me completely down. } \\
\text { (Looks up, but not at therapist) }\end{array}$ & \\
\hline Therapist & $\begin{array}{l}\text { Which thought carries the most meaning for you? } \\
\text { (Still facing patient and taking notes) }\end{array}$ & Identifies the core belief to focus on. \\
\hline Patient & $\begin{array}{l}\text { They are very interconnected, "I'm not good enough"... } \\
\text { (Looks up, but not at therapist) }\end{array}$ & \\
\hline Therapist & $\begin{array}{l}\text { That's the central one, "I'm not good enough". Lets focus on that one. } \\
\text { (Facing the patient, but no eye contact). }\end{array}$ & \\
\hline
\end{tabular}

${ }^{a}$ In order to include all therapist actions investigated, the transcript is developed from typical interactions observed in cognitive therapy at session 4.

bond and less benefit. Webb et al. (2011) found that the bond was marginally important but that when considered in conjunction with agreement on tasks and goals contributed very little to the reduction of symptoms. However, in the Webb et al. study and in the current study, the interplay between bond and agreements dimensions was not studied. As Hatcher and Barends (2006) commented, "Successful collaboration is based on a level of trust and attachment (bond) that is commensurate with the task" (p. 293). That is, in CT particularly, there may be a need for a strong bond before there can be agreement on goals and tasks (Wampold \& Budge, 2012). By the time the alliance is measured, even at Session 3 or 4 , the collaboration may well have moved beyond building trust and forming an agreement about what will happen in therapy so that the importance of the bond, particularly over and above agreement on tasks and goals, is not as critical as it was in the first few moments of the therapeutic engagement (see
Wampold \& Budge, 2012). Indeed, there is experimental evidence that judgments of trust are made in less than one second (Benedetti, 2011). Clearly, longitudinal efforts are needed to determine how the bond, agreement about goals and tasks, and symptom reduction develop interactively over time, in CT and in other therapies.

Throughout the segment of CT presented in Table 7, the cognitive therapist is investigating core beliefs that are tied to feelings. The focus is on descriptions of feelings. The therapist is attuned to and empathic toward the patient. The therapist is, however, not affectively involved, although he is responsive. The therapist does not draw attention to the patient's nonverbal behavior and does not comment on changes in the patient's mood. All these therapists' behaviors were predictive of a good alliance in CT in the study. The behaviors were, however, not predictive of outcome. 
It is interesting to compare the results of the present study with those of Lingiardi et al. (2011), who examined PQS items and the working alliance, as well as session depth. Lingiardi found that several PQS items were associated with the alliance and session depth and concluded that their results "indicate the importance of therapist interventions that focus on the patient's affects, relational patterns, and the "here and now" of the relationship in the increase of the Depth of elaboration and therapeutic alliance" (p. 391). In our study, interventions that focused on affect attenuated the bond and were positively related to outcome only in dynamic therapy. Unfortunately, Lingiardi et al., who used material from independent practice, were not able to investigate the theoretical approach or the outcome of the psychotherapy. These contrasting results suggest the importance of specifying the nature of the treatment being delivered and assessing outcomes.

There are a number of limitations to the present study. First, the patients in this trial were diagnosed with cluster $\mathrm{C}$ personality disorders and were thus avoidant of affective material. Therefore, the results of the present study, particularly with regard to the therapist actions related to affect, may be specific to this population. That is to say, the role of the bond in therapy may well depend on the type of treatment and characteristics of the patient. Second, the reduction in symptoms was assessed by comparing symptoms at the end of treatment to that at the beginning of treatment. Webb et al. (2011) appropriately used the change of symptoms subsequent to measurement of the alliance, but we could not do that unfortunately. However, previous research has demonstrated that the alliance measured early in therapy is not simply a function of early symptom change and continues to predict treatment outcome even when these early changes are controlled for (Barber et al., 2000). Third, the PQS items were selected based on their relationship to the bond, which may capitalize on chance findings, although one of the purposes of this article was to explore which therapist actions lead to formation of the bond. The properties of these items have not been investigated extensively. Moreover, there may be, and likely are, many therapist actions not captured by the PQS that are related to alliance formation. Fourth, this research, as well as Webb et al. (2011), focused on symptom reduction, which may well overemphasize an agreement about tasks focused on particular problems, particularly in CT. It could be that the bond has a different role in benefits of psychotherapy other than symptoms, such as general well being and role functioning (Wampold \& Budge, 2012). Finally, only two treatments were examined and a general theory of the role of the bond across a range of therapies is needed.

The present investigation is distinguished by identifying therapist actions in the first four sessions that affected subsequent ratings of the bond, and the effect of the actions and the bond on outcome. As such it begins to illuminate how therapist actions and the bond work together to produce the benefits of psychotherapy in two different treatments. The results of this study have demonstrated that simple conclusions about the pantheoretical nature of the alliance may be misleading - the alliance seems to be important for all therapies but may well interact with the specific treatment components differently. As such, this research is an effort in understanding what makes psychotherapy work, but clearly additional research on the mechanisms of change in various therapies is needed.

\section{References}

Ablon, J. S., \& Jones, E. E. (1999). Psychotherapy process in the NIMH Collaborative Study. Journal of Consulting and Clinical Psychology, 67, 64-75. doi:10.1037/0022-006X.67.1.64

Ackerman, S. J., \& Hilsenroth, M. J. (2003). A review of therapist characteristics and techniques positively impacting on the therapeutic alliance. Clinical Psychology Review, 23, 1, 33.

Baldwin, S. A., Wampold, B. E., \& Imel, Z. E. (2007). Untangling the alliance-outcome correlation: Exploring the relative importance of therapist and patient variability in the alliance. Journal of Consulting and Clinical Psychology, 75, 842-852. doi:10.1037/0022-006X.75.6.842

Barber, J. P., Connolly, M. B., Crits-Christoph, P., Gladis, L., \& Siqueland, L. (2000). Alliance predicts patients' outcome beyond in-treatment change in symptoms. Journal of Consulting and Clinical Psychology, 68, 1027-1032. doi:10.1037/0022-006X.68.6.1027

Beck, A. T., \& Freeman, A. M. (1990). Cognitive therapy of personality disorders. New York, NY: The Guilford Press.

Benedetti, F. (2011). The patient's brain: The neuroscience behind the doctor-patient relationship. New York, NY: Oxford University Press.

Blagys, M. D., \& Hilsenroth, M. J. (2000). Distinctive activities of shortterm psychodynamic-interpersonal psychotherapy: A review of the comparative psychotherapy process literature. Clinical Psychology: Science and Practice, 7, 167-188. doi:10.1093/clipsy.7.2.167

Blagys, M. D., \& Hilsenroth, M. J. (2002). Distinctive activities of cognitive- behavioral therapy: A review of the comparative psychotherapy process literature. Clinical Psychology Review, 22, 671-706. doi: 10.1016/S0272-7358(01)00117-9

Block, J. (1961). The Q-Sort Method in Personality Assessment and Psychiatric Research. Springfield, IL: Charles C Thomas. doi:10.1037/ 13141-000

Bordin, E. S. (1979). The generalizability of the psychoanalytic concept of the working alliance. Psychotherapy: Theory, Research \& Practice, 16, 252-260. doi: $10.1037 / \mathrm{h} 0085885$

Bordin, E. S. (1980, June). Of human bonds that bind or free. Presidential address to 10th annual meeting of the Society for Psychotherapy Research, Pacific Grove, California.

Bordin, E. S. (1994). Theory and research on the therapeutic working alliance: New directions. In Horvath, A. O. \& Greenberg, L. S. (Eds.), The working alliance: Theory, Research and Practice (pp. 13-37). New York, NY: Wiley.

Cohen, J., \& Cohen, P. (1983). Applied multiple regression/correlation analysis for the behavioral sciences (2nd ed.). Hillsdale, NJ: Erlbaum.

Conger, A. (1974). A revised definition for suppressor variables: A guide to their interpretation and inter prediction. Educational and Psychological Measurement, 34, 35-46. doi:10.1177/001316447403400105

Crits-Christoph, P., Connolly Gibbons, M. B., Hamilton, J., Ring-Kurtz, S., \& Gallop, R. (2011). The dependability of alliance assessments: The alliance-outcome correlation is larger than you might think. Journal of Consulting and Clinical Psychology, 79, 267. doi:10.1037/a0023668

Derogatis, L. (1994). Symptom checklist-90-revised: Administration, scoring, and procedures manual ( $3 r d$ ed.). Minneapolis, MN: National Computer Systems.

Derogatis, L. R., \& Savitz, K. L. (2000). The SCL-90-R and Brief Symptom Inventory (BSI) in primary care. In Maruish, M. E. (Ed), Handbook of psychological assessment in primary care settings. Mahwah, NJ: Erlbaum.

Derogatis, L. R. (1983). SCL-90-R: Administration, scoring and procedures manual, II. Towson, MD: Clinical Psychometric Research.

DeRubeis, R. J., Brotman, M. A., \& Gibbons, C. J. (2005). A conceptual and methodological analysis of the nonspecifics argument. Clinical 
Psychology: Science and Practice, 12, 174-183. doi:10.1093/ clipsy.bpi022

DeRubeis, R. J., \& Feely, M. (1990). Determinants of change in cognitive therapy for depression. Cognitive Therapy and Research, 14, 469-482, doi:10.1007/BF01172968

Diener, M. J., Hilsenroth, M. J., \& Weinberger, J. (2007). Therapist affect focus and patient outcomes in psychodynamic psychotherapy: A metaanalysis. The American Journal of Psychiatry, 164, 936-941. doi: 10.1176/appi.ajp.164.6.936

Diener, M. J., \& Hilsenroth, M. J. (2009). Affect-focused techniques in psychodynamic psychotherapy. In R. A. Levy \& J. S. Ablon (Eds.), Handbook of evidence-based psychodynamic psychotherapy: Bridging the gap between science and practice (pp. 227-247). Totowa, NJ: Humana Press. doi:10.1007/978-1-59745-444-5_10

Dinger, U., Strack, M., Leichsenring, F., Wilmers, F., \& Schauenburg, H. (2008). Therapist effects on outcome and alliance in inpatient psychotherapy. Journal of Clinical Psychology, 64, 344-354. doi:10.1002/ jclp.20443

Feeley, M., DeRubeis, R. J., \& Gelfand, L. (1999). The temporal relation of adherence and alliance to symptom change in cognitive therapy for depression. Journal of Consulting and Clinical Psychology, 67, 578582. doi:10.1037/0022-006X.67.4.578

Flückiger, C., Del Re, A. C., Wampold, B. E., Symonds, D., \& Horvath, A. C. (2012). How central is the alliance in psychotherapy? A multilevel longitudinal meta analysis. Journal of Counseling Psychology, 59, 10 17. doi:10.1037/a0025749

Gaston, L., \& Ring, J. M. (1992). Preliminary results on the inventory of therapeutic strategies (ITS). Journal of Psychotherapy Research and Practice, 1, 1-13.

Hatcher, R. L., \& Barends, A. W. (2006). How a return to theory could help alliance research. Psychotherapy: Theory, Research, Practice, Training, 43, 292-299. doi:10.1037/0033-3204.43.3.292

Hilsenroth, M., Ackerman, S., Blagys, M., Baity, M., \& Mooney, M. (2003). Short-term psychodynamic psychotherapy for depression: An evaluation of statistical, clinically significant, and technique specific change. Journal of Nervous and Mental Disease, 191, 349-357. doi: 10.1097/01.NMD.0000071582.11781.67

Hilsenroth, M., \& Cromer, T. (2007). Clinician interventions related to alliance during the initial interview and psychological assessment. Psychotherapy: Theory, Research, Practice, Training, 44, 205-218. doi: 10.1037/0033-3204.44.2.205

Hoffart, A., Broge, F. M., Sexton, H., Clark, D. M., \& Wampold, B. E. (2012). Psychotherapy for social phobia: How do alliance and cognitive process interact to produce outcome? Psychotherapy Research. doi: $10.1080 / 10503307.2011 .626806$

Horvath, A. O., \& Bedi, R. P. (2002). The alliance. In J. C. Norcross (Ed.), Psychotherapy relationships that work: Therapist contributions and responsiveness to patients (pp. 37-69). New York, NY: Oxford University Press.

Horvath, A. O., Del RE, A. C., Flückiger, C., \& Symonds, D. (2001). Alliance in Individual Psychotherapy, in J. C. Norcross (Ed.), Psychotherapy relationships that work: Evidence-based responsiveness (2nd ed.). New York, NY: Oxford University Press.

Horvath, A. O., Del Re, C., Flückiger, C., \& Symonds, D. (2011). Alliance in individual psychotherapy. Psychotherapy (Chicago, Ill.), 48, 9-16. doi: $10.1037 / \mathrm{a} 0022186$

Horvath, A. O., \& Symonds, B. D. (1991). Relation between working alliance and outcome in psychotherapy: A meta-analysis. Journal of Counseling Psychology, 38, 139-149. doi:10.1037/0022-0167.38.2.139

Horvath, A. O. (2001). The alliance. Psychotherapy: Theory, Research, Practice, Training, 38, 365-372. doi:10.1037/0033-3204.38.4.365

Jones, E. E., Cumming, J. D., \& Horowitz, M. J. (1988). Another look at the nonspecific hypothesis of therapeutic effectiveness. Journal of Con- sulting and Clinical Psychology, 56, 48-55. doi:10.1037/0022006X.56.1.48

Jones, E. E., Hall, S., \& Parke, L. A. (1991). The process of change: The Berkeley Psychotherapy Research Group, In Beutler, L., Crago, M. (Eds.) Psychotherapy research: An international review of programmatic studies. Washington, DC, American Psychological Association, doi:10.1037/10092-011

Jones, E. E., Krupnick, J. H., \& Kerig, P. K. (1987). Some gender effects in a brief psychotherapy. Psychotherapy: Theory, Research, Practice, Training, 24, 336-352. doi:10.1037/h0085724

Jones, E. E., \& Pulos, S. M. (1993). Comparing the process in psychodynamic and cognitive-behavioral therapies. Journal of Consulting and Clinical Psychology, 61, 306-316. doi:10.1037/0022-006X.61.2.306

Jones, E. E. (1985). Manual for the psychotherapy process Q-sort. Unpublished manuscript, University of California, Berkeley, CA.

Klein, D. N., Schwartz, J. E., Santiago, N. J., Vivian, D., Vocisano, C., Castonguay, L. G., . . Keller MB. (2003). Therapeutic alliance in depression treatment: Controlling for prior change and patient characteristics. Journal of Consulting and Clinical Psychology, 71, 997-1006. doi:10.1037/0022-006X.71.6.997

Lambert, M. J., \& Hill, C. E. (1994). Assessing psychotherapy outcomes and processes, in Bergin, A. E., Garfield, S. L. (Eds.) Handbook of Psychotherapy and Behavior Change (4th ed.). New York, John Wiley $\&$ Sons.

Lingiardi, V., Colli, A., Gentile, D., \& Tanzilli, A. (2011). Exploration of session process: Relationship to depth and alliance. Psychotherapy (Chicago, Ill.), 48, 391-400. doi:10.1037/a0025248

Luborsky, L., Barber, J. P., Siqueland, L., Johnson, S., Najavits, L. M., Frank, A., \& Daley, D. (1996). The revised Helping Alliance Questionnaire (HAQ-II). The Journal of Psychotherapy Practice \& Research, 5, 260-271.

Luborsky, L., Crits-Christoph, P., Alexander, L., Margoli, M., \& Cohen, M. (1983). Two helping alliance methods for predicting outcomes of psychotherapy: A counting signs vs. a global rating method. Journal of Nervous and Mental Disease, 171, 480-491. doi:10.1097/00005053198308000-00005

MacKinnon, D. P., Krull, J. L., \& Lockwood, C. M. (2000). Equivalence of the mediation, confounding and suppression effects. Prevention Science, 1, 173-181. doi:10.1023/A:1026595011371

Martin, D. J., Garske, J. P., \& Davis, M. K. (2000). Relation of the therapeutic alliance with outcome and other variables: A meta-analytic review. Journal of Consulting and Clinical Psychology, 68, 438-450. doi:10.1037/0022-006X.68.3.438

McCullough, L., Kuhn, N., Andrews, S., Kaplan, A., Wolf, J., Hurley, C. L., \& Hurley, C. (2003). Treating affect phobia: A manual for short-term dynamic psychotherapy. New York, NY: Guilford Press.

McCullough, L., \& Magill, M. (2009). Affect-focused short-term dynamic therapy. In R. A. Levy \& J. S. Ablon (Eds.), Handbook of evidencebased psychodynamic psychotherapy: Bridging the gap between science and practice (pp. 249-278). Totowa, NJ: Humana Press. doi:10.1007/ 978-1-59745-444-5_11

McCullough Vaillant, L. (1997). Changing character: Short term anxietyregulating psychotherapy for restructuring defenses, affects and attach ment. New York, NY: Basic Books.

Schmitz, N., Hartkamp, N., Kiuse, J., Franke, G. H., Reister, G., \& Tress, W. (2000). The Symptom Check-List-90-R (SCL-90-R): a German validation study. Quality of Life Research: An International Journal of Quality of Life Aspects of Treatment, Care \& Rehabilitation, 9, 185-193. doi:10.1023/A:1008931926181

Svartberg, M., Stiles, T. C., \& Seltzer, M. (2004). Randomized, controlled trial of the effectiveness of short-term dynamic psychotherapy and cognitive therapy for cluster $\mathrm{C}$ personality disorders. The American Journal of Psychiatry, 161, 810-817. doi:10.1176/appi.ajp.161.5.810

Tang, T. Z., \& DeRubeis, R. J. (1999). Sudden gains and critical sessions 
in cognitive-behavioral therapy for depression. Journal of Consulting and Clinical Psychology, 67, 894-904. doi:10.1037/0022-006X .67.6.894

Tomkins, S. S. (1962). Affect, imagery, consciousness. The positive affects (Vol. 1.). New York, NY: Springer.

Tomkins, S. S. (1963). Affect, imagery, consciousness. The negative affects (Vol. 2.). New York, NY: Springer.

Tomkins, S. S. (1991). Affect, imagery, consciousness: The negative affects: Anger and fear (Vol. 3.). New York, NY: Springer.

Tomkins, S. S. (1992). Affect, imagery, consciousness: Cognition: Duplication and transformation of information (Vol. 4.). New York, NY: Springer.

Tzelgov, J., \& Henik, A. (1991). Suppression situations in psychological research: Definitions, implications, and applications. Psychological Bulletin, 109, 524-536. doi:10.1037/0033-2909.109.3.524

Ulvenes, P. G., Berggraf, L., Wampold, B. E., Hoffart, A., \& McCullough, L. (2012). Can two psychotherapy process measures be dependably rated simultaneously? A generalizability study. Submitted for publication.
Wampold, B. E., \& Kim, K.-H. (1989). Sequential analysis applied to counseling process and outcome: A case study revisited. Journal of Counseling Psychology, 36, 357-364. doi:10.1037/0022-0167.36.3.357

Wampold, B. E., \& Budge, S. L. (2012). The Relationship - and it's Relationship to the common and specific factors of psychotherapy. The Counseling Psychologist, 40, 601-623.

Webb, C. A., DeRubeis, R. J., Amsterdam, J. D., Shelton, R. C., Hollon, S. D., \& Dimidjian, S. (2011). Two aspects of the therapeutic alliance: Differential relations with depressive symptom change. Journal of Consulting and Clinical Psychology, 79, 279-283. doi:10.1037/a0023252

Zuroff, D. C., Kelly, A. C., Leybman, M. J., Blatt, S. J., \& Wampold, B. E. (2010). Between-therapist and within-therapist differences in the quality of the therapeutic relationship: Effects on maladjustment and self-critical perfectionism. Journal of Clinical Psychology, 66, 681-697.

Received February 14, 2012 Accepted February 14, 2012

\section{E-Mail Notification of Your Latest Issue Online!}

Would you like to know when the next issue of your favorite APA journal will be available online? This service is now available to you. Sign up at http://notify.apa.org/ and you will be notified by e-mail when issues of interest to you become available! 